\title{
Effect of Intrauterine Growth Restriction on the Number of Cardiomyocytes in Rat Hearts
}

\author{
HUGO BRANDT CORSTIUS, MONIKA A. ZIMANYI, NOORI MAKA, THILOSHINI HERATH, \\ WALTER THOMAS, ARNOUD VAN DER LAARSE, NIGEL G. WREFORD, AND M. JANE BLACK

\begin{abstract}
Department of Cardiology [H.B.C., A.v.d.L.], Leiden University Medical Centre, Leiden 2300 RC, The Netherlands; Department of Anatomy and Cell Biology [M.A.Z., N.M., T.H., N.G.W., M.J.B.], Monash

University, Clayton, Victoria 3800, Australia; and Baker Heart Research Institute [W.T.], Melbourne,
\end{abstract} \\ Victoria 3004, Australia
}

\begin{abstract}
Epidemiologic studies have linked intrauterine growth restriction (IUGR) with an increased incidence of cardiovascular disease later in life; reduced cardiomyocyte number in IUGR hearts may underlie such prenatal programming. Our aim was to examine the effect of IUGR, as a result of maternal protein restriction, on the number of cardiomyocytes in the rat heart at birth. Rats were fed either a low-protein diet (LPD) or a normal-protein diet (NPD) during pregnancy. At birth, the offspring were killed and the hearts were immersion-fixed. The number of cardiomyocyte nuclei in the hearts were stereologically determined using an optical disector-fractionator approach. In some litters, cardiomyocytes were enzymatically isolated from freshly excised hearts and the proportion of binucleated cells was determined. Taking into account the number of binucleated cells, the nuclear counts were adjusted to estimate total cardiomyocyte number. Birth weight and heart weight were significantly reduced in the
\end{abstract}

\section{ABSTRACT}

LPD offspring. This was accompanied by a significant reduction in the number of cardiomyocytes per heart in the LPD offspring compared with the NPD offspring $\left(1.18 \pm 0.05 \times 10^{7}\right.$ and 1.41 $\pm 0.06 \times 10^{7}$, respectively; $\left.p=0.001\right)$. The number of binucleated cardiomyocytes was low $(\sim 3 \%)$ and equal in both groups. In conclusion, IUGR as a result of maternal protein restriction leads to a reduction in the number of cardiomyocytes per heart. As cardiomyocyte proliferation is rare after birth, it is plausible that this reduction in cardiomyocytes may lead to compromised cardiac function later in life. (Pediatr Res 57: 796-800, 2005)
IUGR, intrauterine growth restriction
LPD, low-protein diet
NPD, normal-protein diet
WKY, Wistar Kyoto

Epidemiologic studies have shown a link between low birth weight, as a result of intrauterine growth restriction (IUGR), and an increased incidence of cardiovascular disease later in life (1), suggesting that maternal nutrition may affect the long-term disease profile of offspring. IUGR can result from a lack of nutrients, oxygen, or blood supply to the fetus (2). The link to cardiovascular disease later in life in IUGR infants may relate to underdevelopment of vital organs in utero. Indeed, early studies report that a reduced supply of nutrients during early life, prenatal and postnatal, interferes with the rate of cell multiplication in various organs (3) and that the effect is proportionally more deleterious in tissues with a faster rate of cell multiplication (4). Under these circumstances, growth of the brain is generally "spared" by preferential diversion of

Received January 9, 2004; accepted October 1, 2004

Correspondence: M. Jane Black, Ph.D., Department of Anatomy \& Cell Biology, Post Office Box 13C, Monash University, Victoria 3800, Australia; e-mail: jane.black@med.monash.edu.au.

DOI: 10.1203/01.PDR.0000157726.65492.CD blood flow to the brain, whereas growth of other organs is usually proportional to body weight (5). For example, a reduced kidney weight in IUGR rats was shown to be associated with decreased nephron endowment $(6,7)$. The effects of IUGR on the heart are less well defined. In IUGR rats that are exposed to maternal protein restriction, a reduced heart weight is often found $(8,9)$. Alternatively, an increased heart weight as a result of a low-protein diet (LPD) has also been documented (10). Whether IUGR influences the number of cardiomyocytes in the heart is still unclear. If IUGR is associated with a reduced number of cardiomyocytes at birth, then this could have clinical implications later in life.

Fetal cardiomyocytes undergo both hyperplasia and hypertrophy during growth and maturation of the myocardium $(11,12)$. In early fetal life, cardiomyocyte growth is mainly hyperplastic, but when cardiomyocytes mature during late prenatal or early postnatal life, there is a switch from proliferation to hypertrophy. In rats, cardiomyocytes show a rapidly increasing percentage of binucleated cells during early postnatal growth (13). This is an early morphologic indicator of 
cardiomyocyte hypertrophy as cardiomyocytes respond to the increasing mechanical load of early postnatal development. The cardiomyocytes become mature and "terminally differentiated" and seem to be unable to divide (11).

Although proliferation is a rare event in the adult heart, cardiomyocyte proliferation is not precluded and has been observed in the adult and aging myocardium of rats as a compensatory mechanism to regenerate tissue mass and recover function (14). In humans, myocyte proliferation has also been shown, especially in response to injury as is observed after myocardial infarction $(15,16)$.

During the early postnatal period, the ability of cardiac myocytes to proliferate can be influenced by nutritional, humoral, and hemodynamic factors (17). For instance, slowly growing rats, with subnormal body weight and heart weight as a result of poor neonatal nutrition, have fewer myocytes than rapidly growing rats at $21 \mathrm{~d}$ of age, a change that persists in adults (18-20). In addition, thyroid hormones can inhibit myocyte hyperplasia but promote hypertrophic growth (21). Moreover, increased hemodynamic load, as a result of exposure to carbon monoxide, hypoxia, or hypertension, can result in a heart with more cardiomyocytes $(22,23)$ with less cardiomyocytes than normal (24).

To date, there is little information on the effect of IUGR on cell composition of the heart, particularly the number of cardiomyocytes per heart. Our hypothesis is that IUGR leads to a reduced number of cardiomyocytes at birth and may cause an early onset of cardiac failure in pathologic settings. Therefore, the aim of this study was to determine whether IUGR results in a reduced number of cardiomyocytes per heart in rats at birth. IUGR was induced in offspring by administration of an LPD (9\% casein) during pregnancy. Using this model, we previously observed a $30 \%$ reduction in heart weight in the IUGR offspring (unpublished observations).

\section{METHODS}

Animals and diet treatment. Female and male Wistar Kyoto (WKY) breeder rats were obtained from the Australian Resource Centre (Perth, Australia). The female rats were divided into two groups and fed during pregnancy either a normal-protein diet (NPD) that contained $20 \%$ casein or an LPD that contained $9 \%$ casein. The diets were commercially available, semipurified diets (Glen Forrest Stockfeeders, Glen Forrest, Western Australia). The composition of the diets are shown in Table 1. All breeder rats were habituated to their respective diets for $2 \mathrm{wk}$ before mating. Diet intake was monitored daily. The breeder rats were housed individually and maintained at an ambient temperature of $21^{\circ} \mathrm{C}$ with a $12-\mathrm{h}$ day/night cycle. Food and water was administered ad libitum. For generating the offspring used in this study,

Table 1. Composition of semipurified diets that were fed to dams during pregnancy

\begin{tabular}{lcl}
\hline \multicolumn{1}{c}{$\begin{array}{c}\text { Diet composition } \\
\text { \% by weight) }\end{array}$} & LPD & NPD \\
\hline Casein (acid) & 8.7 & 20 \\
Sucrose & 10 & 10 \\
Starch (total) & 64.41 & 53.11 \\
Cellulose & 5 & 5 \\
Safflower oil & 7 & 7 \\
Methionine & 0.14 & 0.14 \\
Minerals (AIN_93_G) & 3.5 & 3.5 \\
Vitamins (AIN_93_G) & 1 & 1 \\
Choline chloride 50\% (wt/wt) & 0.25 & 0.25 \\
\hline
\end{tabular}

the female breeders were mated (overnight) with the male WKY rats over a staggered time course. The pregnant rats were checked daily. On the day of birth, the pups were weighed and those that selected were for experimentation were killed by cervical dislocation. Ten female offspring from each group were used (derived from five litters in the NPD group and seven litters in the LPD group). Female offspring were randomly selected after abnormally large or small (runt) pups were excluded from the litters. The animal experiments were approved by the Monash University Biochemistry, Anatomy and Microbiology Animal Ethics Committee, and treatment and care of the animals conformed with the Australian Code of Practice for the Care and Use of Animals for Scientific Purposes (25).

Tissue processing. At birth, the hearts were immediately excised, trimmed of excess tissue and fat, and stored in $10 \%$ buffered formalin. The whole hearts were weighed and embedded in glycolmethacrylate resin (Technovit 7100; Kulzers GmbH, Wehrhem/Ts, Germany). The blocks were exhaustively sectioned at $20 \mu \mathrm{m}$ using a Leica RM2165 supercut microtome (Leica Corp., Nusstoch, Germany) fitted with glass Ralph knives, and the total number of sections cut was recorded. Every 10th section was collected, with the first section between one and 10 chosen at random. For more accurately assessing section thickness, the initial and final thicknesses of each block were recorded with a digital micrometer (Mitutoyo, Japan) and the number of sections cut was counted. Sections were mounted on glass slides and placed in a $60^{\circ} \mathrm{C}$ oven for at least $2-3 \mathrm{~d}$. The sections then were stained with hematoxylin in a $1000-\mathrm{W}$ microwave $(50 \%, 2.5 \mathrm{~min})$ and eosin (at room temperature).

Assessment of cardiac tissue volume. For determining cardiac tissue volume, the sampled sections (every 10th section) were projected onto the screen of a Fuji Minicopy Reader (Model RF3A) at a magnification of $\times 24.3$. An orthogonal grid was superimposed over the viewing screen, and the number of grid points $(p)$ overlying the cardiac tissue was counted. The cardiac tissue volume, which included the atria, right and left ventricles, and septum, then was estimated using the Cavalieri principle (26): $\mathrm{V}=S p \times a(p) \times t \times 10$, in which $S p$ is equal to the sum of the intersections with the grid as obtained from all sections, $a(p)$ is the area associated with each grid point, $t$ is the section thickness $(20 \mu \mathrm{m})$, and 10 is the inverse of the sampling fraction (every 10th section was sampled).

Stereologic estimation of the number of cardiomyocyte nuclei. To determine the number of cardiomyocyte nuclei in each heart, we used the optical disector-fractionator combination $(27,28)$. With this method, the effects of shrinkage and swelling artefacts and other technical artefacts such as section compression become irrelevant (29). Provided the cells of interest can be identified and the fraction of tissue used to count cells is known, an unbiased estimate of total number can be made.

All counting was performed using a CASTGRID specialized stereologic system (CAST 2002; Olympus, Albertslund, Denmark). An unbiased counting frame was superimposed over the sections at a magnification of $\times 100$. A systematic uniform random sample of fields was obtained, and nuclei were counted in a "disector" of area $216.7 \mu \mathrm{m}^{2}$ within a depth of $10 \mu \mathrm{m}$ using the upper and lower $5 \mu \mathrm{m}$ of the section as a guard area (to account for inconsistencies in cut surfaces and loss of material). The movement of the stage in the $\mathrm{X}$ and $\mathrm{Y}$ direction was $550 \mu \mathrm{m}$. Nuclei were counted when they came into clear focus within the volume of the disector, so long as no part intersected the forbidden lines. The cardiomyocyte nuclei could be easily identified from other cell types. The cardiomyocyte nuclei were oval, lightly stained with visible chromatin and prominent nucleoli.

The total number of cardiomyocyte nuclei in the heart $\left(N_{c m n}\right)$ was determined as follows: $N_{c m n}=\mathrm{Q}^{-} \times 1 / \mathrm{f}_{1} \times 1 / \mathrm{f}_{2} \times 1 / \mathrm{f}_{3}$, in which $\mathrm{Q}^{-}$is the number of cardiomyocyte nuclei counted, $\mathrm{f}_{1}$ is for the first level of sampling $(1 / 10)$ where every 10 th section was chosen from a random start, $\mathrm{f}_{2}$ is the fraction of the sections in the sampled fields $(216.7 / 550 \times 550)$, and $\mathrm{f}_{3}$ is the third level of sampling within the depth of the section (10/20). The total number of cardiomyocytes in the heart was determined from the nuclear counts, which were adjusted for the percentage of binucleated cardiomyocytes in the heart (method described below).

Binucleation. For the determination of the percentage of binucleated cardiomyocytes in both the LPD and NPD group, another three litters per group were used. After birth, cardiomyocytes were enzymatically isolated from freshly excised hearts (30). The cardiomyocytes then were fixed in $85 \%$ methanol/10\% formalin/5\% acetic acid, smeared onto a slide and stained with hematoxylin and eosin, and analyzed under a light microscope (Olympus BX50, Japan) using a $\times 40$ lens. Five slides were selected from each litter, and a sample of 200 cells from each slide were evaluated to determine the number of binucleated cells present in the sample.

Data analysis. Data were analyzed using SPSS PC version 10 (SPSS Inc., Chicago, IL). Before statistical analysis, all data were tested for normality (Gaussian distribution). All data were found to be normally distributed. To compare data in the LPD group and the NPD group, we used an ANOVA with 
maternal diet (LPD, NPD) as a factor and litter size as a covariate. A $p \leq 0.05$ was considered statistically significant. Results are expressed as means \pm SEM.

\section{RESULTS}

Litter size, birth weight, and heart size. There was no significant difference in litter size between the LPD and NPD litters $(8.3 \pm 0.4$ and $9.6 \pm 0.9$ pups, respectively). Pups that were selected from the LPD litters had a significantly lower mean birth weight compared with the offspring from the NPD group (Table 2). Furthermore, the LPD group showed a significantly reduced heart weight and cardiac tissue volume compared with controls. The reduction in the size of the heart was proportional to the decrease in birth weight such that there was no difference in heart weight to body weight ratio or cardiac tissue volume to body weight ratio between the two groups (Table 2).

Number of cardiomyocyte nuclei. In the low birth weight offspring that were exposed to maternal protein restriction, there was a significant reduction $(p=0.001)$ in the number of cardiomyocyte nuclei in their hearts when compared with offspring in the NPD group (Fig. 1A). There was also a significant dependence of the number of cardiomyocyte nuclei on litter size $(p=0.028)$. It was found that for a litter size of nine pups, the estimated number of cardiomyocyte nuclei per heart was $1.17 \times 10^{7}$ nuclei in the LPD offspring and $1.46 \times$ $10^{7}$ nuclei in the NPD offspring.

Binucleation. The mean number of binucleated cardiomyocytes per 200 cells was $5.87 \pm 0.78$ in the LPD group and 6.33 \pm 0.72 in the NPD group. Thus, the incidence of binucleated cells was low in both groups $(0.029 \pm 0.004$ in the LPD group and $0.031 \pm 0.004$ in the NPD group) and not significantly different.

Number of cardiomyocytes per heart. As seen with estimations of cardiomyocyte nuclei, there was a significant dependence of number of cardiomyocyte cells on litter size $(p=$ $0.028)$, and there was a highly significant reduction ( $p=$ 0.001 ) in the number of cardiomyocytes in the LPD offspring compared with the NPD offspring (Fig. 1B). It was found that for a litter size of nine pups, there were an estimated $1.15 \times$ $10^{7}$ cardiomyocytes in the hearts of the LPD offspring and 1.43 $\times 10^{7}$ cardiomyocytes in the hearts of the NPD offspring.

\section{DISCUSSION}

In this study, there was a proportional reduction in the size of the heart and in the total number of cardiomyocytes in low

Table 2. Birth weight, heart weight, cardiac tissue volume, and ratios of heart weight to body weight and cardiac tissue volume to body weight in LPD and NPD offspring

\begin{tabular}{lrrl}
\hline & \multicolumn{1}{c}{ LPD } & \multicolumn{1}{c}{ NPD } & \\
& \multicolumn{1}{c}{$(n=9)$} & \multicolumn{1}{c}{$(n=10)$} & $p$ \\
\hline Birth weight $(\mathrm{g})$ & $3.56 \pm 0.08$ & $4.31 \pm 0.06$ & $<0.001$ \\
Heart weight $(\mathrm{mg})$ & $22.04 \pm 0.86$ & $24.36 \pm 0.48$ & $<0.05$ \\
Cardiac tissue volume $\left(\mathrm{mm}^{3}\right)$ & $17.49 \pm 0.79$ & $20.20 \pm 0.81$ & $<0.05$ \\
$\begin{array}{c}\text { Heart weight to body weight } \\
\text { ratio }(\mathrm{mg} / \mathrm{g})\end{array}$ & $6.21 \pm 0.29$ & $5.67 \pm 0.15$ & NS \\
$\begin{array}{c}\text { Cardiac tissue volume to body } \\
\text { weight ratio }\left(\mathrm{mm}^{3} / \mathrm{g}\right)\end{array}$ & $4.91 \pm 0.20$ & $4.71 \pm 0.22$ & NS \\
\hline
\end{tabular}

Values are means \pm SEM.
A
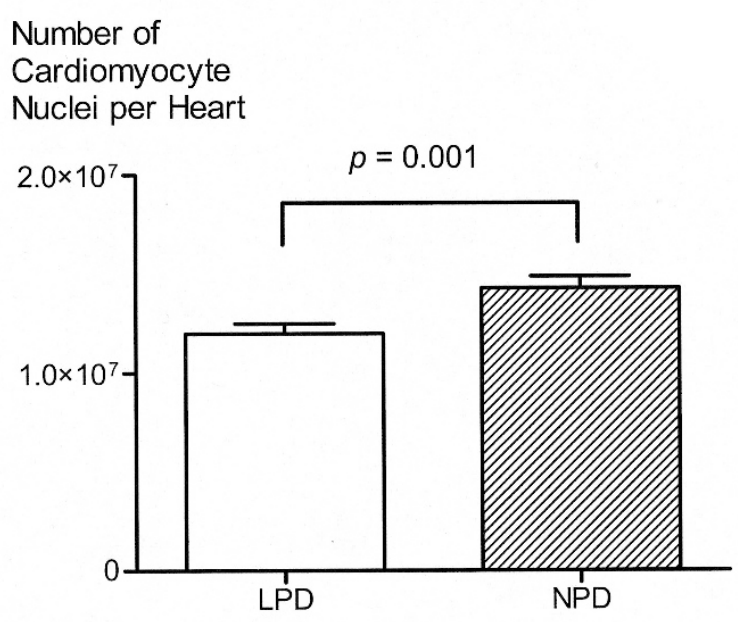

B

\section{Number of Cardiomyocytes per Heart}

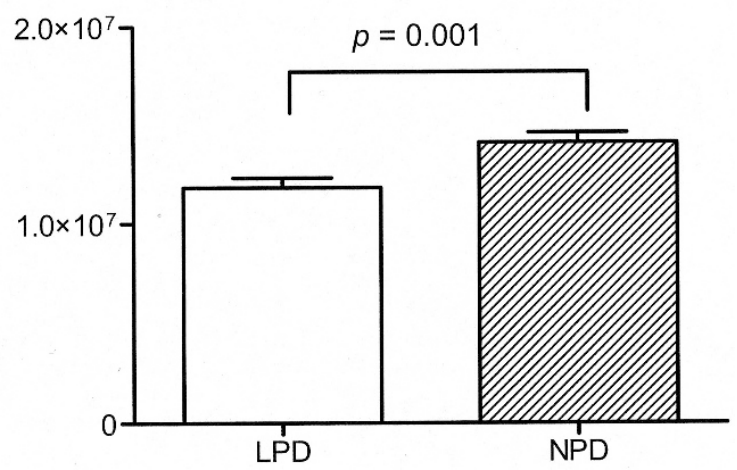

Figure 1. Number of cardiomyocyte nuclei per heart $(A)$ and number of cardiomyocytes per heart $(B)$ in the LPD $(\square ; n=9)$ and NPD (㧩; $n=10)$ groups. Values are means \pm SEM.

birth weight offspring that were exposed to maternal protein restriction when compared with non-growth-restricted controls. The mean estimates of the total number of cardiomyocyte nuclei within the heart (atria and ventricles) obtained in the present study are consistent with measurements from other rat strains. In Sprague-Dawley rats, a mean total cardiomyocyte number of $13.6 \times 10^{6}$ cells has been reported at postnatal day 1 (31). A total of $13.5 \times 10^{6}$ cardiomyocytes (excluding atria) has been reported at postnatal day 1 in Wistar rats (32).

To our knowledge, this is the first study that has reported the effect of IUGR on the number of cardiomyocytes in the heart. We chose to use the optical disector-fractionator technique to count nuclei as this method avoids the effects of shrinkage and/or swelling artefacts, which can occur with tissue processing and fixation.

Stereologic counting methods have been previously applied to investigate ventricular volume and total cardiomyocyte volume in the hearts of IUGR human infants. In these hearts, it was found that fetal weight, ventricular volume, and total cardiomyocyte volume were subnormal for gestational age up 
to $35 \mathrm{wk}$ (33). There was "catch up" in growth between $35 \mathrm{wk}$ and term such that ventricular volumes were not different from those in control subjects at birth. These findings are contrary to the findings in the present study, which demonstrate that heart weights and cardiac tissue volume were significantly reduced at birth. The differences between studies may relate to species differences and/or to the mechanisms by which IUGR was induced.

In humans, IUGR is linked to an increased incidence of heart disease later in life $(4,34)$. The pathways that lead to this increased risk for heart disease are unknown. The IUGRinduced reduction in cardiomyocyte number, observed in the present study, may be involved. Because postnatal growth of the heart is predominantly due to cardiomyocyte hypertrophy, it is plausible that the reduced cardiomyocyte number will remain into adulthood. If this is the case, then the cardiomyocytes in the IUGR heart will have to hypertrophy to a greater extent than normal after catch-up growth. This may lead to impaired cardiac function later in life, especially if the heart is stimulated to hypertrophy, such as after the induction of hypertension. In support of this idea, it was found that spontaneously hypertensive rats that show spontaneous heart failure between 18 and 24 mo of age (35) are born with a lower number of ventricular cardiomyocytes than normotensive rats (24). Hypertension is an established risk factor for pathologic changes in the heart, including loss of cardiomyocytes and increased fibrosis (36). In the IUGR heart that has a reduced capacity to hypertrophy, it is likely that cardiac muscle function will be further compromised.

It must be kept in mind that in the rat species cardiomyocyte hyperplasia continues in the first few weeks postnatally, with only a small proportion of cardiomyocytes binuclear at birth. This was confirmed in the present study. This is different from other species, such as the sheep, in which a high proportion of the cardiomyocytes are binuclear and in their highly differentiated mature form at birth (37), so the chance for postnatal catch-up in cardiomyocyte number is extremely limited in the sheep heart after birth. It is possible, however, that catch-up hyperplasia may occur in the IUGR rat heart after birth. In future studies, it would be interesting to determine whether the reduced cardiomyocyte number in the heart of the IUGR rats persists up until adulthood or there is catch-up hyperplasia early postnatally such that cardiomyocyte number is not compromised in adulthood. It is interesting that in the pig species, cardiomyocyte hyperplasia is not ceased at birth, and it has been shown that neonatal cardiomyocyte proliferation occurs in response to increased load (38), suggesting that catch-up hyperplasia may occur.

In this study, we investigated the effect of IUGR on cardiomyocyte number in the heart of female offspring. On the basis of the findings of previous studies, we expect that the number of cardiomyocytes in male rats should be similar to female rats (18). However, it is possible that IUGR affects the heart in the male in a different way than in the female. Whether this is true requires further investigation. Indeed, there are differences between male and female cardiac growth responses in adulthood, but this could be related to altered hemodynamics and differences in body weights $(39,40)$.
In many rat studies (including the present study), fetal exposure to an LPD is associated with abnormal fetal growth and organ development. The mechanisms by which maternal protein restriction affects heart development are controversial. Endocrine changes in response to nutrient availability (41) and programming of the hypothalamic-pituitary-adrenal axis because of maternal stress (42) may be involved. Alternatively, fetal exposure to glucocorticoids of maternal origin has been proposed to underlie this association (43). In support of this idea, neonatal dexamethasone treatment in rat pups at postnatal days 1-3 causes a permanent decrease in heart weight, as well as hypertrophy and early degeneration of cardiomyocytes during adulthood (44). In addition, prenatal exposure of the premature infant to glucocorticoids, administered to the mother with the purpose of preventing hyaline membrane disease in the infant, may inhibit cardiomyocyte proliferation in utero, resulting in a heart with considerably fewer cardiomyocytes than normal at birth (45). In future studies, it would be interesting to investigate the long-term effects of an IUGRinduced reduction in cardiomyocytes on cardiac function and structure at maturity and after onset of hypertension.

This study has provided evidence that IUGR as a result of maternal protein restriction leads to a reduction in the number of cardiomyocytes. It is conceivable that this may lead to compromised cardiac function later in life and may contribute to the link between IUGR and increased risk for heart disease in adulthood.

Acknowledgments. We gratefully acknowledge Dr. R. Duckett for expert advice in the stereology.

\section{REFERENCES}

1. Barker DJ, Winter PD, Osmond C, Margetts B, Simmonds SJ 1989 Weight in infancy and death from ischaemic heart disease. Lancet 2:577-580

2. Barker DJ 2001 The malnourished baby and infant. Br Med Bull 60:69-88

3. McCance RA, Widdowson EM 1974 The determinants of growth and form. Proc R Soc Lond B Biol Sci 185:1-17

4. Desai M, Crowther NJ, Lucas A, Hales CN 1996 Organ-selective growth in the offspring of protein-restricted mothers. Br J Nutr 76:591-603

5. Lumbers ER, Yu ZY, Gibson KJ 2001 The selfish brain and the Barker hypothesis. Clin Exp Pharmacol Physiol 28:942-947

6. Merlet-Benichou C, Gilbert T, Muffat-Joly M, Lelievre-Pegorier M, Leroy B 1994 Intrauterine growth retardation leads to a permanent nephron deficit in the rat. Pediatr Nephrol 8:175-180

7. Zimanyi MA, Bertram JF, Black JM 2000 Nephron number in the offspring of rats fed a low protein diet during pregnancy. Image Anal Stereol 19:219-222

8. Muaku SM, Thissen JP, Gerard G, Ketelslegers JM, Maiter D 1997 Postnatal catch-up growth induced by growth hormone and insulin-like growth factor-I in rats with intrauterine growth retardation caused by maternal protein malnutrition. Pediatr Res 42:370-377

9. Nutter DO, Murray TG, Heymsfield SB, Fuller EO 1979 The effect of chronic protein-calorie undernutrition in the rat on myocardial function and cardiac function. Circ Res 45:144-152

10. Jackson AA, Dunn RL, Marchand MC, Langley-Evans SC 2002 Increased systolic blood pressure in rats induced by a maternal low-protein diet is reversed by dietary supplementation with glycine. Clin Sci (Lond) 103:633-639

11. Clubb FJ Jr, Bishop SP 1984 Formation of binucleated myocardial cells in the neonatal rat. An index for growth hypertrophy. Lab Invest 50:571-577

12. Oparil S, Bishop SP, Clubb FJ Jr 1984 Myocardial cell hypertrophy or hyperplasia. Hypertension 6:III38-III43

13. Katzberg AA, Farmer BB, Harris RA 1977 The predominance of binucleation in isolated rat heart myocytes. Am J Anat 149:489-499

14. Anversa P, Fitzpatrick D, Argani S, Capasso JM 1991 Myocyte mitotic division in the aging mammalian rat heart. Circ Res 69:1159-1164

15. Leri A, Kajstura J, Anversa P 2002 Myocyte proliferation and ventricular remodelling. J Card Fail 8(suppl):S518-S525 
16. Beltrami AP, Urbanek K, Kajstura J, Yan SM, Finato N, Bussani R, Nadal-Ginard B, Silvestri F, Leri A, Beltrami CA, Anversa P 2001 Evidence that human cardiac myocytes divide after myocardial infarction. N Engl J Med 344:1750-1757

17. Penney DG 1990 Postnatal modification of cardiac development: a review. J Appl Cardiol 5:324-337

18. Bai S, Campbell SE, Moore JA, Morales MC, Gerdes AM 1990 Influence of age, growth, and sex on cardiac myocyte size and number in rats. Anat Rec 226:207-212

19. Hollenberg M, Honbo N, Samorodin AJ 1977 Cardiac cellular responses to altered nutrition in the neonatal rat. Am J Physiol 233:H356-H360

20. Rakusan K, Raman S, Layberrry R, Korecky B 1978 The influence of aging and growth on the postnatal development of cardiac muscle in rats. Circ Res 42:212-218

21. Gerdes AM, Kriseman J, Bishop SP 1983 Changes in myocardial cell size and numbe during the development and reversal of hyperthyroidism in neonatal rats. Lab Invest 48:598-602

22. Clubb FJ Jr, Penney DG, Baylerian MS, Bishop SP 1986 Cardiomegaly due to myocyte hyperplasia in perinatal rats exposed to $200 \mathrm{ppm}$ carbon monoxide. J Mol Cell Cardiol 18:477-486

23. Hollenberg M, Honbo N, Samorodin AJ 1976 Effects of hypoxia on cardiac growth in neonatal rat. Am J Physiol 231:1445-1450

24. van der Laarse A, Bloys van Treslong CH, Vliegen HW, Ricciardi L 1987 Relation between ventricular DNA content and number of myocytes and non-myocytes in hearts of normotensive and spontaneously hypertensive rats. Cardiovasc Res 21:223-229

25. National Health and Medical Research Council (NHMRC) 1997 Australian Code of Practice for the Care and Use of Animals for Scientific Purposes, 6th Ed. Available: www.health.gov.au/nhmrc/research/awc/code.htm

26. Michel RP, Cruz-Orive LM 1988 Application of the Cavalieri principle and vertica sections method to the lung: estimation of volume and pleural surface area. J Microse 150:117-136

27. Gundersen HJ, Bendtsen TF, Korbo L, Marcussen N, Moller A, Nielsen K, Nyengaard JR, Pakkenberg B, Sorensen FB, Vesterby A, West MJ 1988 Some new, simple and efficient stereological methods and their use in pathological research and diagnosis. APMIS 96:379-394

28. Myers M, Britt KL, Wreford NG, Ebling FJ, Kerr JB 2004 Methods of quantifying follicular numbers within the mouse ovary. Reproduction 127:569-580

29. Bertram JF, Nurcombe V 1992 Counting cells with the new stereology. Trends Cell Biol 2:177-180

30. Hannan RD, Stefanovsky V, Taylor L, Moss T, Rothblum LI 1996 Overexpression of the transcription factor UBF1 is sufficient to increase ribosomal DNA transcription in neonatal cardiomyocytes: implications for cardiac hypertrophy. Proc Natl Acad Sci USA 93:8750-8755
31. Li F, Wang X, Capasso JM, Gerdes AM 1996 Rapid transition of cardiac myocytes from hyperplasia to hypertrophy during postnatal development. J Mol Cell Cardiol 28:1737-1746

32. Anversa P, Olivetti G, Loud AV 1979 Morphometric study of early postnatal development in the left and right ventricular myocardium of the rat. I. Hypertrophy, hyperplasia, and binucleation of myocytes. Circ Res 46:495-502

33. Mayhew TM, Gregson C, Fagan DG 1999 Ventricular myocardium in control an growth-retarded human fetuses: growth in different tissue compartments and variation with fetal weight, gestational age, and ventricle size. Hum Pathol 30:655-660

34. Barker DJ 1998 Mothers, Babies and Health in Later Life. Churchill Livingstone, Edinburgh, pp 1-12

35. Boluyt MO, Bing OH, Lakatta EG 1995 The ageing spontaneously hypertensive rat as a model of the transition from stable compensated hypertrophy to heart failure. Eur Heart J 16(suppl N):19-30

36. Diez J, Fortuno MA, Ravassa S 1998 Apoptosis in hypertensive heart disease. Curr Opin Cardiol 13:317-325

37. Burrell JH, Boyn AM, Kumarasamy V, Hseih A, Head SI, Lumbers ER 2003 Maturation of cardiac myocytes in fetal and newborn sheep: a study examining changes in myocyte nuclear number and volume. Anat Rec 274:952-961

38. Beinlich CJ, Rissinger CJ, Morgan HE 1995 Mechanisms of rapid growth in the neonatal pig heart. J Mol Cell Cardiol 27:273-281

39. Pfeffer JM, Pfeffer MA, Fletcher P, Fishbein MC, Braunwald E 1982 Favorable effects of therapy on cardiac performance in spontaneously hypertensive rats. Am J Physiol 242:H776-H784

40. Campbell SE, Rakusan K, Gerdes AM 1989 Change in cardiac myocyte size distribution in aortic-constricted neonatal rats. Basic Res Cardiol 84:247-258

41. Roseboom TJ, van der Meulen JH, Osmond C, Barker DJ, Ravelli AC, SchroederTanka JM, van Montfrans GA, Michels RP, Bleker OP 2000 Coronary heart disease after prenatal exposure to the Dutch famine, 1944-45. Heart 84:595-598

42. Seckl JR 1997 Glucocorticoids, feto-placental 11 $\beta$-hydroxysteroid dehydrogenase type 2, and the early life origins of adult disease. Steroids 62:89-94

43. Langley-Evans SC, Nwagwu M 1998 Impaired growth and increased glucocorticoidsensitive enzyme activities in tissues of rat fetuses exposed to maternal low protein diets. Life Sci 63:605-615

44. de Vries WB, van der Leij FR, Bakker JM, Kamphuis PJ, van Oosterhout MF, Schipper ME, Smid GB, Bartelds B, van Bel F 2002 Alterations in adult rat heart after neonatal dexamethasone therapy. Pediatr Res 52:900-906

45. Rudolph AM 2000 Myocardial growth before and after birth: clinical implications. Acta Paediatr 89:129-133 